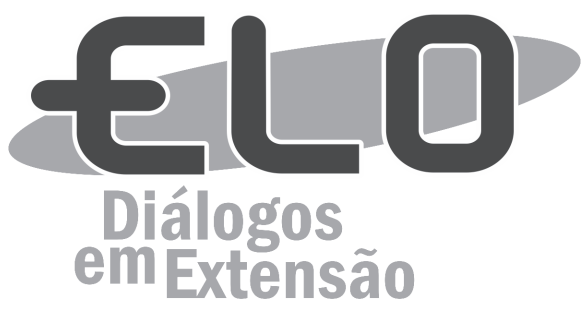

\title{
Projeto xadrez nas escolas: oficinas teórico-práticas para a comunidade
}

\author{
Angela Maria Hartmann ${ }^{1}$, Eliud Lins da Silva Neto², Sara Maria Pereira da Silva ${ }^{3}$, Tierre Batista Migliorin ${ }^{4}$
}

Resumo: O Projeto Xadrez no Campus nasceu na Unipampa, no campus de Caçapava do Sul, RS, há dois anos. Em 2015, a prática enxadrista foi inserida como uma atividade extracurricular em escolas do municipio e como instrumento de desenvolvimento intelectual, da concentração, do raciocínio lógico-matemático e, ainda, do lado emocional e social. O objetivo do Projeto é popularizar o esporte e incentivar estudantes que se destacam nele a representarem suas escolas. As oficinas são teórico-práticas, beneficiando cerca de sessenta estudantes de seis escolas municipais da cidade. O Projeto Xadrez nas Escolas atualmente contempla maior visibilidade na comunidade do município de Caçapava do Sul, tendo boa recepção nas oficinas. Nas edições de 2015, do JESCA e do JERGS, vários alunos do projeto obtiveram premiações. Os bolsistas do projeto também se destacaram em competições, aprimorando o projeto e conquistando espaço nas escolas e no próprio campus.

Palavras-chave: Xadrez. Ensino. Unipampa.

Área Temática: Educação.

\section{Chess project in schools: theory-practice offices for community}

Abstract: The Chess Project Campus was born in Unipampa on the campus of the Caçapava do Sul, RS, two years ago. In 2015, the chess practice was inserted as an extracurricular activity in local schools, as an instrument of intellectual development, concentration and logical and mathematical reasoning, and still, the emotional and social side. The objective of the project is to popularize the sport and encourage students who stand out to represent their schools. The workshops are theoretical-practical, benefiting around sixty students from six local schools of the city. Chess in Schools Project currently includes more visibility of Caçapava do Sul community, with good reception in the workshops. In the editions of 2015, of the JESCA and JERGS, several students of the project obtained awards. Project fellows also excelled in competitions, improving the design and achieving space in schools and at the university.

Keywords: Chess. Education. Unipampa.

\section{Proyecto de ajedrez en las escuelas: teoria-práctica seminarios para la comunidad}

Resumen: El Proyecto de Ajedrez en el Campus nacido en Unipampa, en el campus de Caçapava do Sul, $R S$, hace dos años. Em 2015, la práctica del ajedrez se inserta como una actividad extracurricular en las escuelas locales, como herramienta de desarrollo intelectual, concentración y el razonamiento lógico-matemático, y además, el lado emocional y social. El objetivo del Proyecto es popularizar el deporte y animar a los estudiantes que se destacan para representar a sus escuelas. Los cursos prácticos son teórico-práctico, beneficiando a en

\footnotetext{
${ }^{1}$ Universidade Federal do Pampa (Unipampa); Avenida Pedro Anunciação, 111, Vila Batista, Caçapava do Sul, 96570-000; (55) 3281-9000; angelahartmann@unipampa.edu.br.

2 Universidade Federal do Pampa (Unipampa); Avenida Pedro Anunciação, 111, Vila Batista, Caçapava do Sul, 96570-000; (55) 3281-9000; eliudlinz@gmail.com.

${ }^{3}$ Universidade Federal do Pampa (Unipampa); Avenida Pedro Anunciação, 111, Vila Batista, Caçapava do Sul, 96570-000; (55) 3281-9000; psara.silva@gmail.com.

${ }^{4}$ Universidade Federal do Pampa (Unipampa); Coordenador do Projeto; Avenida Pedro Anunciação, 111, Vila Batista, Caçapava do Sul, 96570-000; (55) 3281-9000;

tierremigliorin@hotmail.com.
} 
torno sessenta estudiantes de seis escuelas municipales de la ciudad. Los proyecto ajedrez en las escuelas actualmente incluye una mayor visibilidade en la comunidade del municipio de Caçapava do Sul, con buena recepción al cursos. En 2015 ediciones, la JESCA y la JERGS, varios estudiantes premios de diseño obtenidos. Los Becarios el proyecto también si destacaron em competiciones, mejorando el proyecto y ganar terreno en las escuelas y en la universidad.

Palabras clave: Ajedrez. Educación. Unipampa.

\section{Introdução}

A utilização do xadrez como instrumento pedagógico tem contribuído para o aprimoramento de habilidades intelectuais e valores éticos dos seus praticantes, proporcionando melhorias significativas no âmbito escolar, com o incremento na capacidade de aprendizado dos discentes. Diversos países, como Rússia, França, Inglaterra, Argentina, Cuba, Venezuela e México, já dispõem do xadrez como ferramenta de estudos nas escolas, seja por meio de projetos, disciplinas ou atividades extracurriculares. A prática do esporte tem sido utilizada com o objetivo de gerar um desenvolvimento intelectual de forma lúdica e interessante para os participantes. Na Romênia, por exemplo, o xadrez é uma disciplina escolar obrigatória e as notas de matemática dependem em $33 \%$ do desempenho dos alunos nas aulas de xadrez, Sá (2005) apud Oliveira (2011).

Diversos estudos (VELOSO-SILVA, 2010; SILVA, 2010; FILGUTH, 2007) têm destacado os benefícios da prática do Xadrez: intelectuais, afetivos e sociais. Segundo Veloso-Silva (2010), a prática do xadrez é dinâmica e provoca mudanças relevantes e benéficas na postura dos jogadores, com o estabelecimento de estratégias dialógicas, cooperativas e interativas, que proporcionam um melhoramento e um empenho maior nos estudos em diferentes áreas do conhecimento. Silva (2010) destaca que o xadrez propicia o desenvolvimento do raciocínio lógico associado à resolução de problemas de Matemática, mas que os discentes, alvo de sua pesquisa, evoluíram não apenas nessa área do conhecimento, mas também em outros componentes curriculares. Sua pesquisa confirma que o xadrez contribui para a melhora do desempenho escolar.

A prática do xadrez contribui para o desenvolvimento de uma atividade de lazer sadia e educativa, que amplia a capacidade lógica e a concentração, utilizando regras do xadrez como forma de contribuir para uma conduta responsável do aluno dentro e fora da sala de aula. Sabe-se que o ensino do xadrez em espaços escolares não acontece em boa parte do Brasil. Em parte, esse fato se deve à falta de pessoas habilitadas para o ensino desse esporte nas escolas.

Na cidade de Caçapava do Sul (RS), essa realidade vem sendo mudada e o número de praticantes do esporte está crescendo, gradualmente, com a contribuição do projeto de ensino de Xadrez no Campus, desenvolvido pela Universidade Federal do Pampa (Unipampa), campus Caçapava do Sul, no ano de 2014. Em 2015, o projeto de ensino de xadrez para acadêmicos do campus, foi transformado em um projeto de extensão que leva o xadrez às escolas, sob a denominação de Xadrez nas Escolas. Atualmente, o projeto abrange a comunidade de alunos de seis escolas do município, sendo desenvolvido em três escolas-polo. Além de vir demonstrando resultados positivos desde a sua implementação, esse trabalho já impulsiona o crescimento de numerosos adeptos dessa prática esportiva.

\section{Objetivos}

O principal objetivo desse projeto de extensão foi difundir a prática do xadrez entre a comunidade local. Assim, o projeto foi aplicado em três escolas-polo do município de Caçapava do Sul - Escola Técnica Estadual Dr. Rubens da Rosa Guedes, Escola Municipal de Ensino Fundamental Nossa Senhora das Graças e Escola Municipal Inocêncio Prates Chaves - além do próprio Campus da Unipampa, Caçapava do Sul. Essas escolas estão localizadas em regiões estratégicas da cidade e são circundadas por escolas menores do entorno, atingindo maior público. Outro objetivo traçado para o projeto foi promover oficinas de xadrez para professores de escolas municipais e estaduais, sendo a oficina realizada, na Semana de Formação Continuado para Professores do município. Ademais, ofereceu-se uma atividade de lazer sadia e educativa para os alunos das escolas participantes, comunidade e discentes da Unipampa, Campus Caçapava do Sul. Além disso, há relatos de professores das escolas sobre a melhora de aprendizado de alguns alunos participantes do projeto. Por fim o projeto promoveu a integração entre universidade e comunidade local. 


\section{Metodologia}

A execução do projeto conta com o auxílio de dois bolsistas que promovem oficinas presenciais para ensinar xadrez e também campeonatos envolvendo alunos de escolas, pessoas da comunidade e discentes da Unipampa. Com auxílio de tabuleiros, jogos de peças, em tamanho oficial e relógio analógico usados em competições, durante as oficinas são desenvolvidos exercícios com o objetivo de apresentar as regras básicas que regem o jogo, simulações de competições e a notação enxadrística. Os participantes do projeto têm aprendido: o movimento das peças (peão, bispo, cavalo, torre, rainha e rei); movimentos especiais (captura, roque, en passant e promoção); tipos de empates (empate, comum acordo, insuficiência de material, lei dos 50 lances, empate por repetição, rei afogado, xeque perpétuo) e a diferença entre xeque e xeque mate.

Além disso, procura-se promover uma abordagem didática que contribua para a compreensão do jogo pelos estudantes, considerando as dificuldades de cada faixa etária. As oficinas têm duração de quatro horas e são realizadas no horário inverso das aulas regulares. Os bolsistas se deslocam para as três escolas-polo durante a semana para ensinar a prática do xadrez a quase sessenta alunos do município. As oficinas são constituídas por módulos que reúnem conceitos teóricos básicos, que são assimilados com a prática do xadrez entre os estudantes, supervisionada pela equipe executora do projeto de extensão. Ao decorrer do curso, conforme desempenho dos praticantes, são introduzidos conceitos mais aprofundados relacionados a competições enxadristas, com exercícios que estimulam a rápida leitura do jogo e exploração de possíveis estratégicas para obter êxito e conseguir vencer a partida.

\section{Resultados e Discussão}

Durante 2014, o projeto foi desenvolvido na modalidade de ensino, a partir do qual se multiplicou o número de acadêmicos praticantes do esporte. Em 2015, a proposta do projeto foi, na modalidade extensão, voltada para alunos, professores de escolas municipais e estaduais da cidade de Caçapava do Sul e pessoas da comunidade interessadas em aprender e/ou praticar o xadrez.

A atividade enxadrista foi difundida de modo que se tornou uma prática mais conhecida no município, promovendo a socialização por meio de um esporte que contribui para ampliar a capacidade de raciocínio e de resolução de problemas. Além disso, surgiram oportunidades e convites para realização de uma oficina presencial para estudantes e professores da Educação Básica; produção de um campeonato de xadrez no campus; produção de resumos e/ou trabalhos acadêmicos para apresentação em eventos acadêmico-científicos.

Dois trabalhos apresentados no VI Salão Internacional de Ensino, Pesquisa e Extensão (Siepe), da Unipampa (SILVA et al. e LANDIM et al., 2014), relatam detalhes do desenvolvimento do projeto, na modalidade de ensino, executado em 2014, e outro resumo aprovado no VII Siepe, ainda não publicado, apresenta a experiência do projeto, na modalidade extensão, no ano de 2015.

Destaca-se, em particular, que os dois bolsistas do projeto Xadrez na Escola desenvolveram, em julho de 2015, uma oficina de formação de professores que visou o aprimoramento de habilidades de professores municipais na prática do xadrez para que eles pudessem aplicá-lo nas suas escolas. A oficina aconteceu no Instituto Municipal de Educação Augusta Maria de Lima Marques e reuniu onze professores de sete escolas do município de Caçapava do Sul/RS.

Além disso, houve um bom desempenho dos alunos das escolas nos Jogos Escolares de Caçapava do Sul (JESCA), em 2015. À procura dos estudantes pelo xadrez foi expressiva durante o evento que teve 99 inscritos nessa modalidade de esporte, distribuídos nas categorias, masculina e feminina, petiz, mirim, infantil e juvenil. Ressalta-se, ainda, que alguns jogadores participantes do projeto foram classificados para a fase estadual e participaram dos Jogos Escolares do Rio Grande do Sul (JERGS). Os bolsistas Sara Maria Pereira da Silva e Eliud Lins Neto, também se mantêm competidores ativos, atuando em várias competições, na categoria universitário. Sara, atualmente, é bicampeã nos Jogos Universitários da Unipampa, além de ter ganhado os Jogos Universitários Gaúchos. Já Eliud é bicampeão dos Jogos Universitários da Unipampa e $7^{\circ}$ colocado nos Jogos Universitários Gaúchos. Ademais, a bolsista Sara participou dos Jogos Universitários Brasileiros de 2014 e 2015, fase nunca alcançada antes. 


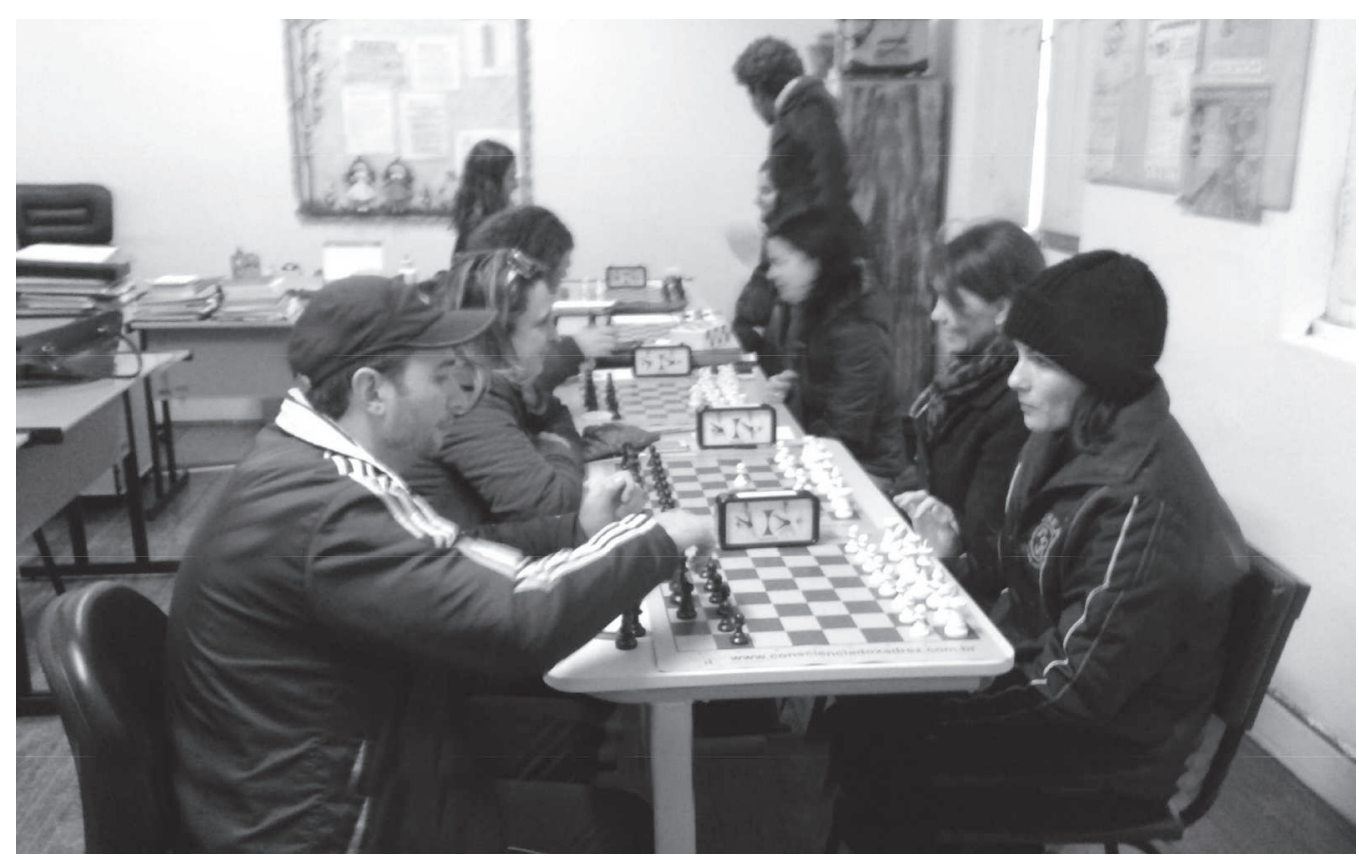

Figura 1 - Capacitação de professores de escolas do município de Caçapava do Sul/RS.

Fonte: Projeto de Extensão Xadrez na Escola.

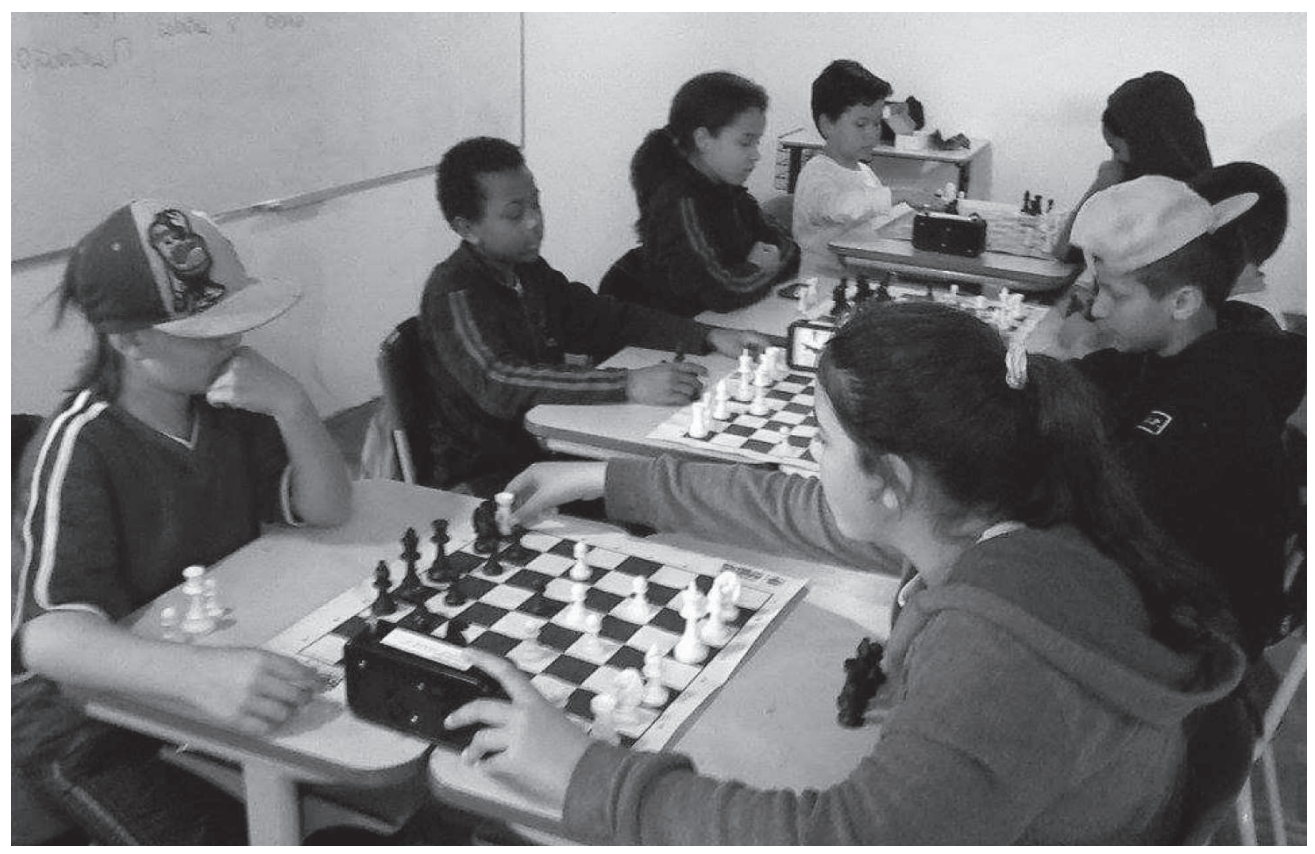

Figura 2 - Alunos da EMEF Inocêncio Prates Chaves em oficina teórico-prática.

Fonte: Projeto de Extensão Xadrez na Escola.

\section{Conclusões}

O projeto de Xadrez conclui seu segundo ano de atividades em dezembro de 2015, sendo fundamental tanto para a formação de estudantes de escolas públicas de Caçapava do Sul quanto para prepará-los para participações em competições. Melhorando o desempenho e aumentando o número de participantes em competições locais, o projeto tem contribuído para o fortalecimento da integração entre universidade e escolas. Como objetivos futuros, pretende-se organizar um torneio entre os participantes dos projetos durante os dois anos de 2014 e 2015 e demais jogadores da cidade de Caçapava do Sul, com o intuito de fomentar a participação dos enxadristas caçapavanos e fortalecer essa comunidade enxadrista. 


\section{Fontes de Financiamento}

O projeto contou em 2015 com duas bolsas (PROEXT) de 20h concedidas pelas Pró-Reitorias de Extensão e Cultura e de Assuntos Estudantis e Comunitários (PRAEC), da Universidade Federal do Pampa- Unipampa.

\section{Referências Bibliográficas}

FILGUTH, R. A importância do xadrez. Porto Alegre: Artmed, 2007.

LANDIM, A. A.; GONÇALVES, L. R. S.; NETO, E. L. S.; HARTMANN, A. M. Projeto Xadrez no Campus: a prática e os benefícios do xadrez para o campus de Caçapava do Sul. VI Salão Internacional de Ensino, Pesquisa e Extensão (SIEPE), da Universidade Federal do Pampa (Unipampa). Bagé, RS, nov. 2014.

SÁ, A. V. M. O Xadrez e a educação experiências nas escolas primárias e secundárias da França. Rio de Janeiro, 1998.

SILVA, L. R. Contribuições do xadrez para o ensino-aprendizagem de Matemática. 2010. $174 \mathrm{f}$. Dissertação (Mestrado). Faculdade de Educação, Universidade de Brasília, 2010.

VELOSO-SILVA, R. R. Práticas pedagógicas no ensino-aprendizagem do jogo de xadrez em escolas. Motriz. Rio Claro, v. 15, n. 3, p. 509-509, jul./set. 2010. 